\title{
Location-based E-Commerce Services: (Re-) Designing using the ISO9126 Standard
}

\author{
Antonia Stefani, Bill Vassiliadis, Theofanis Efthimiades \\ Hellenic Open University \\ Patras, Greece
}

\begin{abstract}
E-commerce services based on user geographic location have emerged as a particularly important segment of modern information services. In these user-intensive applications, quality of service is important and design methods are increasingly relying on software standards to achieve quality. In this paper, we propose an evaluation model for location based e-services that provide insights on how overall system quality can be strengthened via identifying the most important quality characteristics of specific user-system interactions facets. The model categorizes location based services into taxonomies of components / functions, which are further analyzed in interaction facets and significance levels. A further mapping to external qualitative sub-characteristics of the ISO9126 quality standard is used to formally decompose design quality into quality attributes. The view of software design through quality attributes is supported by a mathematical model, which calculates significance weights on service components, defined either by designers or by the end users. An experiment, where this method is used to assess functionality is presented.
\end{abstract}

Keywords-E-commerce; location based services; software quality; software design; ISO9126

\section{INTRODUCTION}

Mobile commerce has grown rapidly in recent years as infrastructure, hardware, and software-supporting technology has dramatically improved its speed and reliability. Mobile devices now offer a plethora of services based on push/pull models of information based on user location. Their energy autonomy and processing power are no longer such serious obstacles as they were in the past and developers have the flexibility to develop resource-demanding software that has in turn, greatly contributed to mobile apps success. Especially mobile e-commerce software offers two unique benefits. It may use either apps or lightly-tailored browsers using well-known user-software interaction patterns, as well as location based services (LBS) that geographically link the real to the virtual world [1].

Competition from e-commerce and e-services vendors has led to the offerings of systems with an ever-increasing complexity. Functional and non-functional requirements recognised at the early design stages of software development are largely based on user expectations and define crucial architectural design decisions. Achieving quality of service, one of the competitive advantages of a modern e-services vendors, depends on the quality performance of specific architectural properties such as functionality, reliability, usability, just to mention a few [2]. In order to make the correct much-needed architectural decisions at the early stages of system design, a certain level of confidence to the results of these decisions is appropriate. One way to achieve this goal is to rely on formal software standards [3].

The quality models defined in ISO standards such as ISO9126 and ISO25010 decompose software quality into characteristics organised into a hierarchical structure in order to facilitate the establishment of requirements and general criteria for their satisfaction [4], [5]. Design quality can therefore be addressed in the terms of how (and how much) quality characteristics influence software components. Targeted design can be achieved by taking decisions that favour the quality of certain components (that may be of most value to end-users) over others. Measurement of quality characteristics, where possible, is valuable to battle against the generality of formal standards and increase practical impact [6].

In this work we propose a Quality Model for designing LBS as sub-systems to e-commerce services. This is a research subject that poses several difficulties in relation to other on-line software, namely the push/pull model of information flow, the interaction with objects based on spatial proximity to the user, managing layers of dynamic information and different interaction facets between users and services [7]. Capturing user requirements and taking design or re-design decisions through evaluation, is one method that ensures user participation in the development process [8], [9].

In order to provide a clearer view of which software components need to be evaluated, the LBS sub-system is analysed in functions/components. The ISO 9126 software evaluation standard was used as the basis for the qualitative assessment, a general standard that can be applied to such systems but has not been widely used in e-commerce businesstype systems to date [10]. A qualitative connection of these components to the characteristics of ISO 9126 is possible in order to pinpoint how each component should be assessed. The result of this step is the definition of a model - quality map of the LBS subsystem [11], [12].

Further refinement of the quality design process includes the categorization of functions into significance levels and facets of user-software interaction. Three levels of significance are identified. The first level includes functions that are considered essential to the user and are technologyindependent (e.g. locating an address). The second level contains important functionality, which is considered desirable from the majority of users (e.g. focus on map points). Finally, the 3 rd level includes functions that are more dependent on the technology used (e.g. road mapping functions). Then the 
functions are categorized into five viewpoints (aspects of user interaction): Presentation, Navigation, Routing, Information and Purchasing. For each characteristic of the system, a correlation function is attributed to depict its relation to the qualitative sub-characteristics of the model. The model defines significance weights for each level, qualitative feature and subfeature. The proposed methodology and the mathematical model that complements it assign weight to the characteristics of the functions/components of the LBS sub-system in order to organize system requirements according to end-user preferences. The later can be used for system re-design or for the design of new systems/sub-systems. The Quality Model can also be used for guided system development since expert/designers may set pre-defined values to model quality parameters and derive appropriate quality requirements. An experiment was contacted for calculating these weights and provides insights on how to use the proposed model.

This paper is structured as follows: in Section II, the basic principles of the Quality Model are presented while in Section III the mapping process of system attributes to the quality characteristics of ISO9126 is explained. The mathematical model used for calculating the correlation between system functions and quality model attributes is also presented. An experiment showcases the application of the method in Section IV and conclusions are drawn in Section V.

\section{QUALITY MODEL}

\section{A. Rational and Structure}

The software subsystem (LBS of e-commerce system) is analysed into a set of basic functions. These functions are either explicitly mentioned in the requirements document and/or may include functions that are desirable (to be included in the system). It is the case in many software development projects that desirable configurations are either not possible to achieve due to time or budget constraints or may not be actually popular with users [13]. A software's added value, as viewed in general quality management principles is increased, theoretically, with the number of (new) features it possesses. In the case of e-services, features usually correspond to functionality. There is a tendency to design services with many functions, however, setting a goal for quality over a large number of functions poses a stress to project resources and project management [2]. There is a need for a structured and organised method to achieve quality over interdependent functionality taking into account user expectations. Targeted quality design helps designers to better understand how different system functionality influences overall system quality or even allows them to adjust the design so as to achieve a certain degree of influence. This adjustment may come as a result of project development limitations, special requirements by specific target groups, application of agile methods to software development or technical limitations [14]. The quality of the different parts of the system should also be influenced by user expectations i.e. of what is considered qualitative for which component. The quality map of the system should also address the problem of how the overall quality of the system is influenced by its components. To answer this question, one needs to identify the components and evaluate their contribution to quality. This is mainly answered by the users; they are usually mainly concerned with the set of available functions (addressed by the Functionality quality characteristic of ISO9126) and their quality (addressed by Quality in Use) [3], [15]. We extend the model presented in [11] to include a more comprehensive link between the processes of software analysis and design and the production and use of the system quality map. We further configure the model to address LBS specific quality issues.

Using a divide and conquer strategy, the services are analysed in their basic functionality (during the analysis phase of the software development lifecycle). They are further organised into significance levels and facets of user-system interactions. Significance levels are useful for incorporating a ranking of services importance, a prioritization mainly derived from the designer team knowledge of the business and technical context in which the services will operate. Prioritization also helps achieve economy of scale where needed resources are not timely available or not available at all. Facets further organise functions into categories of system-user interaction taxonomies where the type of interaction (and not significance per se) is considered. User perception of quality is introduced by calculating weights that quantify the contribution of significance of each function to the overall system quality. This is a user's view of the system quality. It is furthered detailed by the mapping of functions to quality characteristics and sub-characteristics of ISO9126 and the assignment of weights to the mapping relations. The model permits the specific targeting of quality sub-characteristics for each function (setting quality sub-goals). Strong relationships, that is high values of a weight for function A to quality subcharacteristics $\mathrm{x}$, means that the development team should take specific steps to reach this goal. The nature of the subcharacteristic itself provides general guidelines on what is considered qualitative. Quality sub-goals are set depending on the resources available, the technology used, the experience and knowledge and of the quality culture of the development team. To this end, either the top two weights (as per value) for each function may be considered or a cut-off value to indicate whether a mapping relationship is strong or weak. Strong relationships help define general design goals (global quality goals), a process somewhat not straightforward. Trade-offs surely exists between sub-goals depending on technological and/or methodological factors.

The process that derives the system quality map (the Quality Model) is depicted in Fig. 1. The phase of analysis (system breakdown to functions), taxonomy build-up (organisation of functions according to significance level and facets) corresponds to analysis tasks of the software development lifecycle. Calculation of weights and mapping correspond to early design tasks. The weighting phase requires the gathering of knowledge of how users perceive software quality. The gathering process must take place either during the analysis of requirements using methods such as user surveys, benchmarking, expert reviews and by taking advantage of the corporate knowledge in the specific context of use. Specifically for LBS, three significance levels and four main facets are considered in this process (a fifth facet is considered not mandatory). 


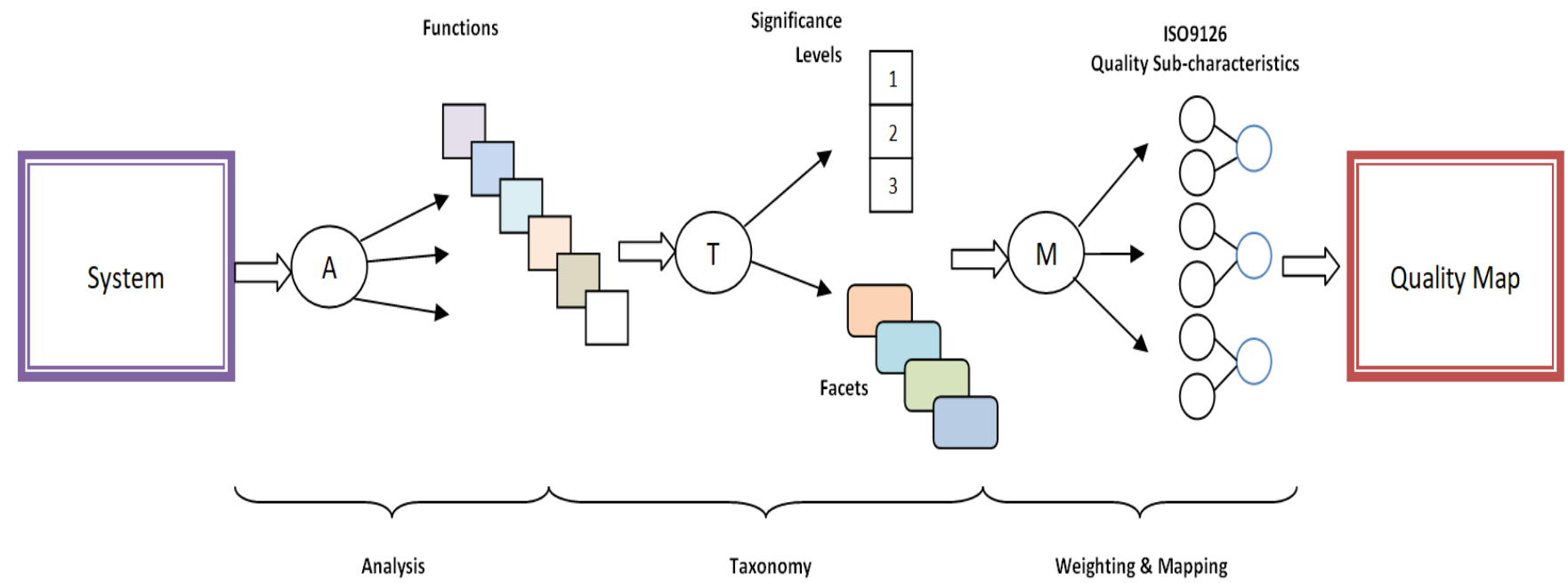

Fig. 1. The process that produces the quality map.

TABLE I. LOCATION BASED SERVICES FunCTIONS

\begin{tabular}{|c|c|}
\hline Service & Description \\
\hline $\begin{array}{l}\text { Map view/My } \\
\text { Location }\end{array}$ & $\begin{array}{l}\text { Location of the user in a map is presented with an } \\
\text { accuracy of a few meters based on GPS or Wi-Fi } \\
\text { data. }\end{array}$ \\
\hline $\begin{array}{l}\text { Point of Interest } \\
(\text { POI })\end{array}$ & $\begin{array}{l}\text { Search and locate any Points of Interest (POI) close } \\
\text { to the user location or in a broader geographical area. }\end{array}$ \\
\hline $\begin{array}{l}\text { Directions } \\
\text { (routing) }\end{array}$ & $\begin{array}{l}\text { Providing directions from a starting point to a } \\
\text { destination using various means of transportation. It } \\
\text { is possible to use the current position of the user or } \\
\text { any other persons as the starting point, by entering } \\
\text { the postal address or by selecting a point on the map. }\end{array}$ \\
\hline Locate Friends & $\begin{array}{l}\text { Find friends located nearby and communicate with } \\
\text { them using social networking applications. }\end{array}$ \\
\hline $\begin{array}{l}\text { Mode } \\
\text { (Transit and/or } \\
\text { walking directions) }\end{array}$ & $\begin{array}{l}\text { Information on routes for the user to travel by bus or } \\
\text { train, as well as provision of walking directions. This } \\
\text { feature requires information from transport } \\
\text { organizations, who have to update the system in real } \\
\text { time. }\end{array}$ \\
\hline Street view & $\begin{array}{l}\text { A } 3 \mathrm{D} \text { visual feature with pictures of the actual road, } \\
\text { as it was captured at an earlier time. Through the } \\
\text { mobile phone, the user can see the real image of a } \\
\text { selected point of interest, as well as have a more } \\
\text { general view of the street in which it is located. }\end{array}$ \\
\hline Traffic & $\begin{array}{l}\text { A real-time update of traffic conditions on user- } \\
\text { selected roads, providing assistance in choosing the } \\
\text { fastest route. }\end{array}$ \\
\hline Apps connection & $\begin{array}{l}\text { The ability to wirelessly forward emails, calendar } \\
\text { entries, and phonebooks from the sub-system to the } \\
\text { e-commerce system or an external app }\end{array}$ \\
\hline
\end{tabular}

The use of appropriate quality mechanisms to assess the external quality of the system (quality as it is perceived by the final users) is an important objective in each evaluation. Evaluation methods deliver better results when used to evaluate specific components of the system by prioritizing a qualitative goal [2]. The interpretation of measurements and the contribution of quality sub-characteristics to the assessment of the quality of the system are the elements that determine its mapping to software functions. The need to select the appropriate mapping (function to quality sub-characteristic) for the assessment of each component can be viewed in terms of a user-centred approach that satisfies basic principles of quality in use: how the software behaves when operated by the users. In order to evaluate the external quality, interaction facets (similar to the stakeholder viewpoints of a system architecture in ISO42010: 2011 [16]) were applied so as to better identify how the system responds to user actions. A set of basic LBS functions are depicted in Table I. These services are further analysed into functions, which correspond to specific facets.

\section{B. The Navigation Facet}

The Navigation facet includes mechanisms that support user navigation on a map. The interaction between the user and the LBS is either in a one-dimensional mode (for example, using a stylus on a touch screen) or in a multidimensional mode (for example, a combination of voice and motion). The user's navigation capabilities in the application generally include the following features:

a) Move within map: The user may gradually move within the map in different directions by moving the stylus on the touch screen or navigating to the appropriate menu, displaying the areas of interest.

b) Focusing on map points or areas: The user can focus on map points or expand areas without changing the content of the displayed information. The areas shown in the screen are either stored off-line or they are downloaded in real-time.

c) Hide / Show Points: The user can hide or highlight certain objects or classes of objects (friends or points of 
interest) displayed on the map by selecting them with the stylus or the appropriate combination of keys.

d) Analysis of points of interest: The user chooses a point of interest and retrieves information about it from the corresponding database maintained by the data provider.

e) Viewing settings: The user can change the viewing angle and parameters related to the graphical display such as colour, font of texts and symbols, terrain map contrast (day / night mode), display dimensions (2D or 3D), defining the values of the variables within the allowed limits.

f) Dialog window: The user, through the activation of dialogs, introduces his / her preferences and interests by changing the way it interacts with the application (e.g. chooses to disable voice instructions).

g) Search: Based on one or more criteria, the user can search for comparable entities or POIs by using the appropriate dialog box.

h) Shortcuts: Many application functions can be executed via the alphanumeric keypad, since the selection of certain keys corresponds to a specific action performed by the app.

i) Help: The user can learn about the way the application works.

\section{The Routing Facet}

The Routing facet includes mechanisms and methods that serve the user and system interaction when using map navigation services. The basic requirement of a user of a platform that implements map navigation services is to find a way of moving from one point to another, by deciding on the best route from a set of alternatives. The main parts of a route are the starting point, the various legs of the route and the destination. The starting point and the destination are determined by the following mechanisms:

a) My location: The current location of the user, as calculated by the positioning system (Wifi, GSM, GPRS or GPS), may be the starting point or destination of the route.

b) Point selection: The user selects the point on the map from which a route will start or end.

c) Point Search: Using the appropriate dialog, the user enters the desired mailing address to be used as the starting point or destination.

d) History: Points searched by the user in chronological order, starting from the most recent, can be the starting point or destination of the route.

e) Favourites: By storing "favourite" points on the map, the user can use them by referring to the appropriate list.

f) Friend position: The location of a friend identified by the system is a possible starting point or final destination of a route.

Concerning the route per se, the following methods of interaction are usually provided:

g) Direction: By taking into account the selected start and arrival points selected by the user, the application, computes the route, showing it on the map, highlighting the nodal points and providing information identifying it. It also creates a list of detailed directions from the starting point, the intermediate points, to the final destination.

h) Transit: The user is informed about the time required to reach the destination using a particular route and based on the start time, calculates the time of arrival at the destination depending on the transport means selected. It also depicts the exact time each hub will be reached, based on traffic conditions, and if necessary, modify the route to be followed.

i) Walking: The route between two points can be determined, taking into account that the user has selected the pedestrian mode. In this case, the routing is not affected by road traffic and the shorter path is calculated more directly. reversed.

j) Reverse: The starting point and the destination can be

\section{The Presentaion Facet}

Presentation includes the functions the system uses to present information to the user, including area maps. The goal of this facet is the comprehensive presentation of information using images, three-dimensional representations and sound. In an application that implements map navigation services, the user interface must provide the user with specific information, such as static map images of the selected area, user location on the map information about points of interest (friends or mobile objects), as well as directions on a route. A navigation service platform is required to present the requested information in the following ways:

a) Maps: Graphical representation of a geographical area using a road or terrestrial / satellite map. The map may include various information elements: (i) the route drawn from the selected starting point or the current location of the user to the selected destination; (ii) the points of interest and the road using three-dimensional graphics; (iii) colouring strongly specific streets depending on information such astraffic and iv) the location of the user and that of his friends as well as the location of various entities / objects (such as the home or the car of the user).

b) Photos: View photos of roads and points of interest.

c) Text: Use of text to describe a point of interest (postal address, historical data), user status (speed, altitude, geographic coordinates of its location, if it is pedestrian or not) and a selected route, indicating route directions, intermediate and endpoints.

d) d. Voice: Use of voice instructions to allow the user to navigate a route or enter the route itself (starting point and destination).

\section{E. The Information Facet}

This facet includes the methods by which the user is aware of information other than the design and implementation of a route and the mechanisms by which this information affects the user interface. Besides the user's basic requirement for route creation, an essential feature is also the information about entities and situations that are located upon the area where the route is situated. The key elements of the information provided are the following: 
a) Update placement of moving / fixed entities: The user navigating trough the geographical map of the area or through the list of POIs is informed about the location of friends and objects of interest.

b) Traffic update: The user is informed about traffic conditions and special events (e.g. traffic jams) in selected roads by referring to the corresponding map.

c) Route / Billing Update: The user is informed about the potential charges (e.g. tolls) on various routes.

d) POI related information: By selecting a point of interest from a search result, the user is informed about features such as its location on the map, its postal address and various contact details (phone, e- mail, web site), the distance from public transport hubs and routes, the type and cost of the services it provides, as well as user comments. In addition, it is possible to view photos of the point of interest and the streets where it is located.

\section{F. The Purchasing Facet}

This optional facet supports B2C (business to Consumer) and G2C (Government to Consumer) processes. Points of Sales $(\mathrm{PoS})$ are located through various push/pull modes. In pull mode, PoS are located in the map (in the area or point of interest) or they appear in the results of a user search. In push mode, a PoS appears in the map when the user enters an area geographically close to it. In push mode, the LBS sub-system can be configured to include/exclude objects based on user preferences, friends' recommendations or based on the existence of special offers.

The user goes through the following steps to make a purchase: i) location of PoS (push/pull mode), ii) purchase of service or product either via the parent application or by accessing an external, app or web store and iii. delivery of the purchased service. The facet includes features that support directly the purchasing process. Features that are related to navigation are not included (e.g. browsing through a list of PoS or services).

\section{G. Levels of Significance}

The quality model uses three levels of significance: the first level of significance includes, by definition, the functions that support the user regardless of the interaction medium. The 2 nd level contains functions that the user desires. Finally, the third level includes the functions associated with the technological characteristics of the system. The three-tier structure allows the Quality Model to be expanded so as to be applicable to related or new, evolving systems, such as virtual reality imaging systems.

Level 1 includes those components and functions, which must be included in each navigation application, and their existence is independent of the technology used to support the system. Functions of this level include: 1) my location, 2) the point search on the map, and 3) the route along with routing directions. The basic requirement of a user navigating a map is to acquire information on the various routes a selected point can be reached and how. For this reason, the integration and implementation of the above functions is crucial for the system's success and for quality assurance.

The 2nd level includes functions that are not that basic but are desirable by the user (or necessary to be included in the sub-system by the designers). They may be incorporated into the sub-system without requiring special technological specifications. They incorporation to the system however does increase overall system quality. Additional functionalities and services at this level enhance user and system interaction. The basic user requirement satisfied in this level includes functions that inform the user of what objects are located around him, and additional information about those objects. Appropriate mechanisms to facilitate these interactions are used such as 1) history, 2) favourites, 3) walking, 4) inversion, 5) location of fixed entities and 6) information about points of interest.

Level 3 includes advanced operations, which depend on the hardware and software technology that the application uses to implement it. Technology dependence refers to not only software and hardware compatibility but to performance factors as well. At this level, functions correspond to user requirements for advanced product features and their implementation requires the use of advanced networks and devices capable of utilizing fast data processing and storage systems. The functions included at this level are: 1) 3D representation of routes or POS, 2) finding a friend (requires installation of specific software by all parties involved, 3) realtime updates on transit using public transport (requires connection between the provider's network and the transport operator), 4) real-time updates about traffic information (requires connection to traffic management centres G2C services 5) information on routes and charges for public transport (requires a connection between the provider's network and the transport operator). Usually, traffic and billing information are not provided in real time but correspond to known patterns (e.g. heavy traffic is expected in main city routes in early morning hours) or somewhat out of date information from other sources.

\section{MAPPING PROCESS}

\section{A. Mapping Functions to ISO9126 Characteristics}

The Quality Model maps the functions and components of the system to the external characteristics and sub- of the ISO 9126 quality standard. The standard includes four quality characteristics (Table II).

The above-mentioned attributes determine the end user's view of the features and services provided by the system and can be used when interacting with it. ISO25010 [5] provides a similar, albeit more detailed, classification of characteristics/sub-characteristics that still remain to be tested for their practical value [17]. 
TABLE II. ISO9126 KEY QUALITY CHARACTERISTICS

\begin{tabular}{|l|l|}
\hline Quality Characteristic & Description \\
\hline Functionality & $\begin{array}{l}\text { The ability of the software to provide all the required functions under defined and real conditions. It refers to the } \\
\text { definition of the functions that the software should provide to meet user needs. The significance of the above feature is } \\
\text { summarized in the question: "What are the functions of the software that meet user needs?". }\end{array}$ \\
\hline Reliability & The ability of the software to operate in a fixed and specific manner under defined conditions. \\
\hline Efficiency & The ability of the software to operate under defined conditions. \\
\hline Usability & $\begin{array}{l}\text { The characteristic of the software of being easy to use. Ease of use can be measured by how quickly a task is performed, } \\
\text { how many mistakes are made, how quickly the software is learned and how satisfied final users are when using it. }\end{array}$ \\
\hline
\end{tabular}

\section{B. The Mapping Function}

A key element of the Quality Model is the definition of the correlation between the components/functions of the system with the external qualitative sub-features of the ISO9126:

\section{(Component) x (Quality Feature)}

This formula creates a two-dimensional table for each one of the three levels of significance defined previously. The correlation between a component/function of the system with a particular sub-feature is determined by the correlation function (CF) $r_{i j}$ (where $i$ defines the component for each interaction facet and $j$ defines the qualitative sub-characteristic of ISO9126). The set of values for the function is binary, either zero or one. If there is no (strong) correlation between a component and a sub-characteristic, then the function value is zero (denoted by ' $\mathrm{O}$ ' in the table), otherwise it is ' 1 ' (denoted by ' $\mathrm{X}$ ' in the table).The value of $\mathrm{CF}$, and consequently the correlation between the two parameters in the table that is formed, is determined by expert evaluators or system designers. It can be redefined when a new function/component is introduced or it can be set so as to depict a quality design goal.

\section{Mapping Table: The Functionality Quality Characteristic}

Tables III, IV and V depict the functions/components of the three facets grouped in the significance levels 1, 2 and 3, as well as the correlation with the qualitative sub-characteristic of Functionality.

The Quality feature of Functionality refers to the set of functions that support user-system communication. Similar mapping takes places for the remaining three characteristics of ISO9126 (Reliability, Usability and Efficiency). Actually, the mapping process is compatible with all ISO hierarchical standards. The functions provided need to meet the needs and requirements of the user by implementing navigation, retrieval and processing of data and information. The realisation of these functions answers the question of 'what is the user able to do when interacting with the system?' The user, generally has the ability to use the service through text, images, audio, 3D imaging and graphics. The two key elements through which the user accesses the information are maps and text. Sophisticated devices also provide visualization and voice guidance mechanisms, enhancing application functionality and increasing the range of services offered. In each software application, including map navigation applications, the way the user navigates through menus and pages is a key element in assessing the quality of each software system whether it uses the web to implement it or not.
TABLE III. $\quad 1^{\text {ST }}$ LEVEL MAPPING FOR FUNCTIONALITY

\begin{tabular}{|c|c|c|c|c|}
\hline \multicolumn{5}{|c|}{ Functional Suitability } \\
\hline \multirow[b]{2}{*}{ Level 1} & \multicolumn{4}{|c|}{ Sub-characteristic } \\
\hline & Suitability & Precision & Interoperability & Security \\
\hline & \multicolumn{4}{|c|}{ Correlation $r_{i j}$} \\
\hline \multicolumn{5}{|c|}{ Presentation Facet } \\
\hline $\begin{array}{l}\text { Maps } \\
\text { (routing) }\end{array}$ & $\mathrm{X}$ & $\mathrm{X}$ & $X$ & $\mathrm{O}$ \\
\hline $\begin{array}{l}\text { Maps (user } \\
\text { position) }\end{array}$ & $\mathrm{X}$ & $\mathrm{X}$ & $\mathrm{X}$ & $\mathrm{X}$ \\
\hline $\begin{array}{l}\text { Text info } \\
\text { (info tags) }\end{array}$ & $\mathrm{X}$ & $\mathrm{X}$ & $\mathrm{X}$ & $\mathrm{O}$ \\
\hline \multicolumn{5}{|c|}{ Navigation Facet } \\
\hline $\begin{array}{l}\text { Move within } \\
\text { map }\end{array}$ & $X$ & $\mathrm{X}$ & $\mathrm{O}$ & $\mathrm{O}$ \\
\hline Focus & $X$ & $X$ & $\mathrm{O}$ & $\mathrm{O}$ \\
\hline $\begin{array}{l}2 \mathrm{D} \\
\text { presentation }\end{array}$ & $\mathrm{X}$ & $\mathrm{O}$ & $\mathrm{X}$ & $\mathrm{O}$ \\
\hline $\begin{array}{l}\text { Dialog } \\
\text { Screens }\end{array}$ & $\mathrm{X}$ & $\mathrm{O}$ & $X$ & $\mathrm{X}$ \\
\hline Help & $\mathrm{X}$ & $\mathrm{O}$ & $\mathrm{O}$ & $\mathrm{O}$ \\
\hline \multicolumn{5}{|l|}{ Routing Facet } \\
\hline My position & $\mathrm{X}$ & $\mathrm{X}$ & $X$ & $\mathrm{X}$ \\
\hline $\begin{array}{l}\text { Search for } \\
\text { POI/PoS }\end{array}$ & $\mathrm{X}$ & $\mathrm{X}$ & $\mathrm{X}$ & $\mathrm{O}$ \\
\hline Show route(s) & $\mathrm{X}$ & $\mathrm{X}$ & $X$ & $\mathrm{O}$ \\
\hline \multicolumn{5}{|c|}{ Information Facet } \\
\hline $\begin{array}{l}\text { POI } \\
\text { information }\end{array}$ & $\mathrm{X}$ & $\mathrm{X}$ & $\mathrm{X}$ & $\mathrm{O}$ \\
\hline \multicolumn{5}{|c|}{ Purchasing Facet } \\
\hline $\begin{array}{l}\text { PoS } \\
\text { information }\end{array}$ & $X$ & $\mathrm{X}$ & $\mathrm{X}$ & $\mathrm{X}$ \\
\hline
\end{tabular}

A basic parameter of navigation is the manipulation of maps, the use of menus and the interchange between the classic app user interface and the map's user interface. Other mechanisms such as indexes and appropriate dialogs help the user navigate anywhere in the application. Also embedded search engines provide the ability to find information by entering keywords or parameter queries using logical operators. Important parameters in the search and processing of information are the correlation and relevance of the data 
retrieved in relation to the query and the response rate of the application to user requests.

The routing process is based on the location of the user and on the ability to provide routes to POI or PoS around it based on his/her preferences and needs. The information process includes the mechanisms by which the user retrieves information about entities of interest, without necessarily referring to destination of a route, but also information about a situation such as a traffic jam.

TABLE IV. $\quad 2^{\mathrm{ND}}$ LEVEL MAPPING FOR FUNCTIONALITY

\begin{tabular}{|c|c|c|c|c|}
\hline \multicolumn{5}{|c|}{ Functionality } \\
\hline \multirow[b]{2}{*}{ Level 2} & \multicolumn{4}{|c|}{ Sub-characteristic } \\
\hline & Suitability & Precision & Interoperability & Security \\
\hline & \multicolumn{4}{|c|}{ Correlation $r_{i j}$} \\
\hline \multicolumn{5}{|c|}{ Presentation Facet } \\
\hline $\begin{array}{l}\text { Maps } \\
\text { (POIs) }\end{array}$ & $X$ & $X$ & $X$ & $\mathrm{O}$ \\
\hline $\begin{array}{l}\text { Maps } \\
\text { (Object } \\
\text { location) }\end{array}$ & $X$ & $\mathrm{X}$ & $X$ & $\mathrm{X}$ \\
\hline $\begin{array}{l}\text { Text info } \\
\text { (POI/user } \\
\text { info tags) }\end{array}$ & $\mathrm{O}$ & $\mathrm{O}$ & $X$ & $\mathrm{O}$ \\
\hline \multicolumn{5}{|c|}{ Navigation Facet } \\
\hline Focus & $\mathrm{X}$ & $\mathrm{X}$ & $\mathrm{O}$ & $\mathrm{O}$ \\
\hline $\begin{array}{l}\text { Hide/Show } \\
\text { POIs }\end{array}$ & $\mathrm{X}$ & $\mathrm{O}$ & $\mathrm{O}$ & $\mathrm{O}$ \\
\hline $\begin{array}{l}\text { Analyse } \\
\text { POI }\end{array}$ & $X$ & $\mathrm{O}$ & $\mathrm{X}$ & $\mathrm{O}$ \\
\hline $\begin{array}{l}\text { Dialog } \\
\text { Input } \\
\text { Screens } \\
\end{array}$ & $\mathrm{X}$ & $\mathrm{O}$ & $\mathrm{X}$ & $\mathrm{X}$ \\
\hline Shortcuts & $\mathrm{O}$ & $\mathrm{O}$ & $X$ & $\mathrm{O}$ \\
\hline \multicolumn{5}{|c|}{ Routing Facet } \\
\hline History & $\mathrm{X}$ & $\mathrm{O}$ & $\mathrm{O}$ & $\mathrm{X}$ \\
\hline Favourites & $\mathrm{X}$ & $\mathrm{O}$ & $\mathrm{O}$ & $\mathrm{X}$ \\
\hline $\begin{array}{l}\text { Mode } \\
\text { (Pedestrian, } \\
\text { Car etc.) } \\
\end{array}$ & $\mathrm{X}$ & $\mathrm{O}$ & $\mathrm{O}$ & $\mathrm{O}$ \\
\hline Reverse & $\mathrm{X}$ & $\mathrm{O}$ & $\mathrm{O}$ & $\mathrm{O}$ \\
\hline \multicolumn{5}{|c|}{ Information Facet } \\
\hline $\begin{array}{l}\text { POI } \\
\text { position }\end{array}$ & $\mathrm{X}$ & $\mathrm{X}$ & $\mathrm{X}$ & $\mathrm{O}$ \\
\hline $\begin{array}{l}\text { POI } \\
\text { detailed } \\
\text { information }\end{array}$ & $\mathrm{X}$ & $\mathrm{X}$ & $\mathrm{X}$ & $\mathrm{O}$ \\
\hline \multicolumn{5}{|c|}{ Purchasing Facet } \\
\hline $\begin{array}{l}\text { PoS } \\
\text { detailed } \\
\text { information }\end{array}$ & $\mathrm{X}$ & $\mathrm{X}$ & $\mathrm{X}$ & $\mathrm{X}$ \\
\hline
\end{tabular}

TABLE V. $\quad 3^{\text {RD }}$ LEVEL MAPPING FOR FUNCTIONALITY

\begin{tabular}{|c|c|c|c|c|}
\hline \multicolumn{5}{|l|}{ Functionality } \\
\hline \multirow[b]{2}{*}{ Level 3} & \multicolumn{4}{|c|}{ Sub-characteristic } \\
\hline & Suitability & Precision & Interoperability & Security \\
\hline & \multicolumn{4}{|c|}{ Correlation $r_{i j}$} \\
\hline \multicolumn{5}{|c|}{ Presentation Facet } \\
\hline $\begin{array}{l}\text { Maps -3D } \\
\text { road view }\end{array}$ & $\mathrm{X}$ & $\mathrm{X}$ & $\mathrm{X}$ & $\mathrm{O}$ \\
\hline $\begin{array}{l}\text { Maps- } \\
\text { Satellite } \\
\text { view }\end{array}$ & $\mathrm{X}$ & $\mathrm{X}$ & $\mathrm{X}$ & $X$ \\
\hline $\begin{array}{l}\text { Maps - } \\
\text { traffic } \\
\text { information }\end{array}$ & $\mathrm{O}$ & $\mathrm{O}$ & $X$ & $\mathrm{O}$ \\
\hline $\begin{array}{l}\text { Maps - } \\
\text { friends } \\
\text { close by }\end{array}$ & $\mathrm{X}$ & $\mathrm{O}$ & $\mathrm{O}$ & $\mathrm{O}$ \\
\hline $\begin{array}{l}\text { User status } \\
\text { info (speed, } \\
\text { direction, } \\
\text { coordinates) }\end{array}$ & $\mathrm{X}$ & $X$ & $X$ & $\mathrm{O}$ \\
\hline \multicolumn{5}{|c|}{ Navigation Facet } \\
\hline $\begin{array}{l}\text { Voice } \\
\text { command }\end{array}$ & $\mathrm{X}$ & $\mathrm{X}$ & $\mathrm{O}$ & $\mathrm{O}$ \\
\hline $\begin{array}{l}\text { Change } \\
\text { map view } \\
\text { angle }\end{array}$ & $X$ & $X$ & $\mathrm{O}$ & $\mathrm{O}$ \\
\hline \multicolumn{5}{|c|}{ Routing Facet } \\
\hline $\begin{array}{l}\text { Routing to } \\
\text { friend } \\
\text { position } \\
\text { (moving } \\
\text { POI) }\end{array}$ & $\mathrm{X}$ & $\mathrm{O}$ & $X$ & $X$ \\
\hline $\begin{array}{l}\text { Re-routing } \\
\text { (user on the } \\
\text { move) }\end{array}$ & $X$ & $\mathrm{X}$ & $\mathrm{O}$ & $\mathrm{O}$ \\
\hline \multicolumn{5}{|c|}{ Information Facet } \\
\hline $\begin{array}{l}\text { Update } \\
\text { moving } \\
\text { POIs } \\
\text { position }\end{array}$ & $\mathrm{X}$ & $\mathrm{X}$ & $X$ & $\mathrm{O}$ \\
\hline $\begin{array}{l}\text { Update real- } \\
\text { time traffic } \\
\text { conditions }\end{array}$ & $\mathrm{O}$ & $\mathrm{O}$ & $\mathrm{X}$ & $\mathrm{O}$ \\
\hline $\begin{array}{l}\text { Update real- } \\
\text { time traffic } \\
\text { events }\end{array}$ & $\mathrm{O}$ & $\mathrm{O}$ & $\mathrm{X}$ & $\mathrm{O}$ \\
\hline \multicolumn{5}{|c|}{ Purchasing Facet } \\
\hline Purchase & $\mathrm{X}$ & $\mathrm{X}$ & $X$ & $\mathrm{X}$ \\
\hline
\end{tabular}

\section{Mathematical Model}

Let $\pi_{x}$ be a quality characteristic of ISO9126, with $\mathrm{x}=1,2,3,4$. Thus, $\pi_{l}$ is the Functionality quality characteristic of ISO9126. Let $\lambda\left(\pi_{x}\right)$ be the number of quality sub-characteristics of quality characteristic $\pi_{x}$ e.g. from the ISO1926 definition [4], it holds that $\lambda\left(\pi_{1}\right)=4$. 
Let $\beta_{\Pi x, j}$ denote the significance weight of a subcharacteristic (SCSW) taking values in the interval [0,1], for the quality characteristic $\pi_{x}$ and for its quality sub-characteristic $\mathrm{j}\left(\mathrm{j}=1 . . \lambda\left(\pi_{x}\right)\right)$.

It holds that:

$\pi_{\mathrm{x}} \sum_{\mathrm{j}=1}^{\lambda\left(\pi_{\chi}\right)} \beta_{\pi_{\mathrm{x}, \mathrm{j}}}=1$

This means that the sum of the SCSWs for each qualitative characteristic equals to 1, e.g. for Functionality that includes four sub-characteristics, it holds:

$\beta_{1,1}+\beta_{1,2}+\beta_{1,3}+\beta_{1,4}=1$

The same holds for $\beta_{\Pi x}$ which denotes the significance weight of a characteristic (CSW).

Let $\mathrm{F}_{\mu}$ denote the facet $(\mu=1 . .5)$ and $\mathrm{L}_{\mathrm{i}}$ the level of significance $(\mathrm{i}=1 . .3)$. Let $\mathrm{W}_{\mathrm{F} \mu, \mathrm{Li}}$ (taking values in the interval [0..1]) denote the Total Significance Weight (TSW) for facet $F_{\mu}$ and significance level $\mathrm{L}_{\mathrm{i}}$. Then it holds that for each quality characteristic, the sum of all TSW equals to 1, for each facet, e.g. it holds that:

$\mathrm{W}_{\mathrm{F} 1, \mathrm{~L} 1}+\mathrm{W}_{\mathrm{F} 1, \mathrm{~L} 2}+\mathrm{W}_{\mathrm{F} 1, \mathrm{~L} 3}=1$

Where $F_{1}$ is the Presentation Facet and $L_{1}-L_{3}$ the three levels of significance.

Using these definitions, the quality assessment model defines significance weights for characteristics (CWS) and subcharacteristics (SCWS), which express the emphasis that needs to be given during system analysis and design. The value of the weight of each feature depends on the emphasis system designers wish to give to a system based on expert opinion, since this is more of a strategic decision. For example, a strategic design decision would be to emphasize more on suitability than on precision. Furthermore, it defines significance weights for facets per significance level (TSW). This weight denotes the emphasis designers wish to give on basic functions of the system (significance level 1) or advanced functions (levels 2 and 3). Users determine these values directly.

The correlation function takes a numeric value (SW) based on the results of the experiment. Let $\sigma_{\beta}$ denote the SW of component/function $(\sigma)$. Then, for the interaction facet $F_{\mu}$ and for the significance level $\mathrm{L}_{\mathrm{i}}$ that corresponds to the quality subcharacteristic $\lambda\left(\pi_{x}\right)$ of the quality characteristic $\pi_{x}, \mathrm{SW}$ is calculated by the formula:

$\sigma_{\beta}=\sum_{j=1}^{\lambda\left(\pi_{x}\right)} r_{i j} \beta_{\Pi_{x, j}}$

The normalized values of $\mathrm{SW}, \kappa \sigma_{\beta}$ take values in the interval $[0,1]$.

At the quality characteristic level, the Composite Significance Weight (CSW) $\mathrm{w}_{\sigma}$ is used, that is the combined SWs of each function per significance level per facet per quality characteristic:

$w_{\sigma}=\kappa \sigma_{\beta} * \beta_{\pi_{x}} * W_{F_{\mu}, L_{i}}$

\section{EXPERIMENT}

\section{A. Experiment Setup}

Following the first stage of the development of the model, which included the determination (by an expert on quality) of the correlation function between the system components and the four external qualitative sub-characteristics of ISO9126, the second step details the value of this correlation (strength of relation). The Composite Significance Weight (CSW) for each function-quality characteristic relation is defined as the qualitative value of the structural elements of the model as given by normalized numerical values in the interval $[0,1]$. The values of SW were calculated using two methods a) through the judgment / opinion of an evaluator; and b) through an experiment involving users executing predefined scenarios. User data were collected using a structured questionnaire. The values set by the evaluator and the resulting values from the completion of the user responses were combined using the Quality Model's mathematic formula to extract the final CSW.

The mobile application used in the experiment was the Google Maps app, an app that is considered both popular and user-friendly. A variety of platforms and operating systems was used including smartphones equipped with the Windows Mobile operating system or the Android OS, GPS receiver, touchscreen and wireless $4 \mathrm{G}$ data transfer protocols. The user sample surveyed included 5 experienced users who had used at least 10 times the specific or similar navigation applications. Users were asked to perform 12 specific multi-step scenarios in a predefined way, evaluating the quality of the components of the quality model when interacting with the system. The tests were designed to include only the functions/components of the app implemented in Greece, excluding some functions such as real-time traffic update (which, although supported by the Greek version of the app, real time updating is not supported) or in app purchases using PoS. Following the scenario enactment, users completed a structured questionnaire (the Likert type rating scale was used), evaluating the system's operation in real conditions. Users evaluated all ISO9126 characteristics and sub-characteristics for all LBS functions/components detailed in Section II. Evaluation was organised per facet and per level of significance. Correlations that were not recognised were evaluated with ' 0 ' and with a '-' (dash) if the function/component was not included in the performed scenario.

\section{B. Calculating and Assigning Values}

The correlation table was initially defined by the evaluator before user participation. However, from the processing of the user questionnaires, differences in estimates were observed for some functions/components leading to a slightly updated version of the table. In the current experiment, there was a chance that few discrepancies and/or inaccurate responses may influence overall results so the parameter values were categorised into two evaluation clusters. The first cluster of values was formed based on the expert estimates and the other on user responses. Normalized significance weights were calculated by using the table of values of significance weights for each qualitative sub-characteristic resulting from the first two processing steps, as well as the correlation tables of users and evaluator. The resulting significance weights were 
calculated separately based on both the user association table and the evaluator table. If no operation was performed by any user, then a dash ('-') was the corresponding weight value for that component / function. The calculation of the composite weight of significance was performed by taking into account the significance weights of each qualitative characteristic (initially a weight of 0.25 / characteristic was assigned) and the weights of each significance level (initially a weight of $0.6,0.3$ and 0.1 was assigned to each of the $1^{\text {st }}, 2^{\text {nd }}$ and $3^{\text {rd }}$ levels, respectively). This process was based on the correlation tables of both the users and the evaluator. If a component had not been assigned a value, then it was not evaluated and the corresponding cell was filled-in with a dash ('-').

\section{Experiment Results}

The resulting final tables depict the app functions/components with assigned CSW values, sorted by level, appearance and quality characteristic, for each of the three significance levels (depicted in Tables VI-VIII for significance levels 1,2 and 3 , respectively). These tables present values assigned by the users.

TABLE VI. $\quad 1^{\text {sT }}$ LeVEl Composite SignificANCE WeIGHTS VAlues

\begin{tabular}{|c|c|c|c|c|}
\hline \multicolumn{5}{|l|}{ ISO9126 } \\
\hline \multirow[b]{2}{*}{ Level 1} & \multicolumn{4}{|c|}{ Characteristics } \\
\hline & Functionality & Usability & Performance & Reliability \\
\hline & \multicolumn{4}{|c|}{ Composite Significance Weight $(W \sigma)$} \\
\hline \multicolumn{5}{|c|}{ Presentation Facet } \\
\hline $\begin{array}{l}\text { Maps } \\
\text { (routing) }\end{array}$ & 0,038 & 0,0375 & 0,050 & 0,038 \\
\hline $\begin{array}{l}\text { Maps (user } \\
\text { position) }\end{array}$ & 0,038 & 0,0375 & 0,050 & 0,038 \\
\hline $\begin{array}{l}\text { Text info } \\
\text { (info tags) }\end{array}$ & 0,037 & 0,0375 & - & 0,038 \\
\hline \multicolumn{5}{|c|}{ Navigation Facet } \\
\hline $\begin{array}{l}\text { Move } \\
\text { within map }\end{array}$ & 0,025 & 0,025 & 0,038 & 0,026 \\
\hline Focus & 0,025 & 0,025 & - & 0,026 \\
\hline $\begin{array}{l}\text { 2D } \\
\text { presentation }\end{array}$ & 0,025 & 0,025 & 0,038 & 0,026 \\
\hline $\begin{array}{l}\text { Dialog } \\
\text { Screens }\end{array}$ & 0,025 & 0,025 & 0,038 & 0,026 \\
\hline Help & 0,025 & 0,025 & - & 0,019 \\
\hline \multicolumn{5}{|c|}{ Routing Facet } \\
\hline My position & 0,041 & - & 0,050 & 0,050 \\
\hline $\begin{array}{l}\text { Search for } \\
\text { POI/PoS }\end{array}$ & 0,041 & 0,075 & 0,050 & 0,050 \\
\hline $\begin{array}{l}\text { Show } \\
\text { route(s) }\end{array}$ & 0,041 & 0,075 & 0,050 & 0,050 \\
\hline \multicolumn{5}{|c|}{ Information Facet } \\
\hline $\begin{array}{l}\text { POI } \\
\text { information }\end{array}$ & 0,15 & 0,15 & 0,15 & 0,15 \\
\hline \multicolumn{5}{|c|}{ Purchasing Facet } \\
\hline $\begin{array}{l}\text { PoS } \\
\text { information }\end{array}$ & 0,10 & 0,10 & 0,10 & 0,10 \\
\hline
\end{tabular}

TABLE VII. $\quad 2^{\text {ND }}$ LEVEL COMPOSITE SIGNIFICANCE WeIGHTS VALUES

\begin{tabular}{|c|c|c|c|c|}
\hline \multicolumn{5}{|l|}{ ISO9126 } \\
\hline \multirow[b]{2}{*}{ Level 2} & \multicolumn{4}{|c|}{ Characteristics } \\
\hline & Functionality & Usability & Performance & Reliability \\
\hline & \multicolumn{4}{|c|}{ Composite Significance Weight $(W \sigma)$} \\
\hline \multicolumn{5}{|c|}{ Presentation Facet } \\
\hline $\begin{array}{l}\text { Maps } \\
\text { (POIs) }\end{array}$ & 0,0226 & 0,019 & 0,019 & 0,019 \\
\hline $\begin{array}{l}\text { Maps } \\
\text { (Object } \\
\text { location) }\end{array}$ & 0,0226 & 0,019 & 0,019 & 0,019 \\
\hline $\begin{array}{l}\text { Text info } \\
\text { (POI/user } \\
\text { info tags) }\end{array}$ & 0,0220 & 0,019 & 0,019 & 0,019 \\
\hline \multicolumn{5}{|c|}{ Navigation Facet } \\
\hline Focus & 0,015 & 0,015 & 0,025 & 0,015 \\
\hline $\begin{array}{l}\text { Hide/Show } \\
\text { POIs }\end{array}$ & 0,015 & 0,015 & - & 0,015 \\
\hline $\begin{array}{l}\text { Analyse } \\
\text { POI }\end{array}$ & 0,015 & 0,015 & 0,025 & 0,015 \\
\hline $\begin{array}{l}\text { Dialog } \\
\text { Input } \\
\text { Screens }\end{array}$ & 0,015 & 0,015 & 0,025 & 0,015 \\
\hline Shortcuts & 0,015 & 0,015 & - & 0,015 \\
\hline \multicolumn{5}{|c|}{ Routing Facet } \\
\hline History & 0,019 & 0,025 & 0,019 & 0,015 \\
\hline Favourites & 0,019 & - & 0,019 & 0,020 \\
\hline $\begin{array}{l}\text { Mode } \\
\text { (Pedestrian, } \\
\text { Car etc.) }\end{array}$ & 0,018 & 0,025 & 0,019 & 0,020 \\
\hline Reverse & 0,018 & 0,025 & 0,019 & 0,020 \\
\hline \multicolumn{5}{|c|}{ Information Facet } \\
\hline $\begin{array}{l}\text { POI } \\
\text { position }\end{array}$ & 0,038 & 0,038 & 0,038 & 0,038 \\
\hline $\begin{array}{l}\text { POI } \\
\text { detailed } \\
\text { information }\end{array}$ & 0,038 & 0,038 & 0,038 & 0,038 \\
\hline \multicolumn{5}{|c|}{ Purchasing Facet } \\
\hline $\begin{array}{l}\text { PoS } \\
\text { detailed } \\
\text { information }\end{array}$ & 0,038 & 0,038 & 0,038 & 0,038 \\
\hline
\end{tabular}

Results of this particular experiment demonstrate the fact that the evaluation based on both the users and the evaluator, in defining the correlation function, are largely yielded almost the same ordering of system components/function (Table IX). As far as Functionality is concerned, the most basic functions/components were highly rated thus analysts, designers and engineers should attach great importance to their quality analysis and design. Considering basic user requirements, locating ones position searching and managing POIs and creating alternative routes were positively evaluated. Excluding usability, there were no significant differences between the results from the users' and evaluator's correlation estimates. The most valuable functions/component were the 
indication of POIs, while followed by the presentations of the route through maps for users and POI search. The most efficient and reliable function/components were the provision of information on points of interest. Therefore, the most qualitative components are those that serve the basic functions expected to support a navigation application.

The overall conclusion from this experiment was that the specific application provides all the necessary functions for the large majority of users, and is deemed reliable (except from cases where the position of the user was not pinpointed with the same accuracy, re-routing algorithms took much longer time to calculate alternatives than anticipated and real-time data was not available). Usability seemed to be a concern especially for users with small screen devices where information overload seemed to be a problem, especially when moving. Users also rely more and more on additional information for $\mathrm{POI} / \mathrm{PoS}$, especially on other peoples' opinion and ratings. A careful interpretation of the results produces user requirement categorised by a formal qualitative perspective and thus helps designers of an existing app to develop a better new version.

TABLE VIII. $3^{\text {RD }}$ LEVEL Composite SignificANCE WeIGHTS VALUeS

\begin{tabular}{|c|c|c|c|c|}
\hline \multicolumn{5}{|l|}{ ISO9126 } \\
\hline \multirow[b]{2}{*}{ Level 3} & \multicolumn{4}{|c|}{ Characteristics } \\
\hline & Functionality & Usability & Performance & Reliability \\
\hline & \multicolumn{4}{|c|}{ 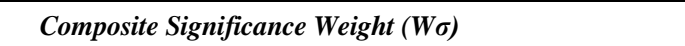 } \\
\hline \multicolumn{5}{|c|}{ Presentation Facet } \\
\hline $\begin{array}{l}\text { Maps -3D } \\
\text { road view }\end{array}$ & 0,038 & 0,038 & 0,019 & 0,019 \\
\hline $\begin{array}{l}\text { Maps- } \\
\text { Satellite } \\
\text { view }\end{array}$ & 0,06 & 0,008 & 0,008 & 0,008 \\
\hline \begin{tabular}{l}
\multicolumn{1}{c}{ Maps - } \\
traffic \\
information
\end{tabular} & 0,04 & 0,008 & 0,008 & 0,006 \\
\hline $\begin{array}{l}\text { Maps - } \\
\text { friends close } \\
\text { by }\end{array}$ & 0,06 & 0,008 & 0,008 & 0,006 \\
\hline $\begin{array}{l}\text { User status } \\
\text { info (speed, } \\
\text { direction, } \\
\text { coordinates) }\end{array}$ & 0,005 & - & - & - \\
\hline \multicolumn{5}{|c|}{ Navigation Facet } \\
\hline $\begin{array}{l}\text { Change } \\
\text { map view } \\
\text { angle }\end{array}$ & 0,012 & 0,013 & 0,013 & 0,013 \\
\hline \multicolumn{5}{|c|}{ Routing Facet } \\
\hline $\begin{array}{l}\text { Routing to } \\
\text { friend } \\
\text { position }\end{array}$ & 0,008 & 0,010 & 0,013 & 0,013 \\
\hline $\begin{array}{l}\text { Re-routing } \\
\text { (user on the } \\
\text { move) }\end{array}$ & 0,009 & 0,010 & 0,013 & 0,013 \\
\hline \multicolumn{5}{|c|}{ Information Facet } \\
\hline $\begin{array}{l}\text { Update } \\
\text { moving } \\
\text { POIs } \\
\text { position }\end{array}$ & 0,009 & 0,013 & 0,017 & 0,013 \\
\hline
\end{tabular}

\section{DISCUSSION AND CONCLUSIONS}

Systems that use location based sub-systems combine software applications, hardware and networks to provide a high level of interaction with the user. LBS-enabled services are aimed at a broad spectrum of mobile users and thus, the capture, organisation, classification and satisfaction of user requirements during the analysis and (re-)design phases are a challenge.

Users interacting with such systems seek ease of use, fast responses, autonomy, financial gain, enjoyable navigation experience tailored to their personal needs. The degree to which user requirements are satisfied affects the success of a system and characterize its quality of use. The quality of LBSenabled systems can be evaluated against quality of applications that support the system and quality services provided by the system. Evaluating systems based on quality is a means to derive (ever-changing) user requirements than may, in turn, be used to re-design a system or design a new one. To this end, evaluation can be approached using two complementary perspectives: the evaluation of the functions supported by the software and the evaluation of the services provided to the user. The evaluation of software functions requires specialized knowledge and can be performed by software engineers who can also act as evaluators. Experts are able to contribute to the hierarchical analysis of quality from general to partial. However, the user of exerts will not suffice, software must also be evaluated by the final users during its use.

TABLE IX. ThE TOP-3 QUALITY FunCTIONS PER FACET

\begin{tabular}{|c|c|c|c|}
\hline \multirow[b]{2}{*}{ Facet } & \multirow[b]{2}{*}{ Top 3} & \multicolumn{2}{|l|}{ Function/Component } \\
\hline & & $\begin{array}{l}\text { Correlation } \\
\text { (Users) }\end{array}$ & $\begin{array}{l}\text { Correlation } \\
\text { (Experts) }\end{array}$ \\
\hline \multirow{3}{*}{ 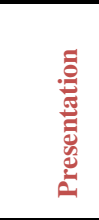 } & 1 & Map (routing) & Map (routing) \\
\hline & 2 & Map (POI) & Map (POI) \\
\hline & 3 & Map (road view) & $\begin{array}{l}\text { Text info } \\
\text { (POI/user info tags) }\end{array}$ \\
\hline \multirow{3}{*}{ 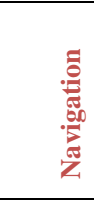 } & 1 & Move within map & Move within map \\
\hline & 2 & Focus & Hide/Show POIs \\
\hline & 3 & Change map view angle & $\begin{array}{l}\text { Change map view } \\
\text { angle }\end{array}$ \\
\hline \multirow{3}{*}{ 胞 } & 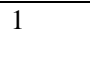 & Search for POI/PoS & Search for POI/PoS \\
\hline & 2 & Reverse & Reverse \\
\hline & 3 & Favourites & $\begin{array}{l}\text { Mode } \\
\text { (Pedestrian, Car etc.) }\end{array}$ \\
\hline \multirow{3}{*}{ 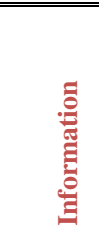 } & 1 & POI position & POI position \\
\hline & 2 & POI information & POI information \\
\hline & 3 & $\begin{array}{l}\text { Update moving POIs } \\
\text { position }\end{array}$ & $\begin{array}{l}\text { POI detailed } \\
\text { information }\end{array}$ \\
\hline
\end{tabular}


In this paper we presented a Quality Model that identifies and analyzes the basic components of location-based enabled e-commerce software, and determines their correlation to ISO 9126 quality features. The model's goal is to detailed analysis of the quality of the user's requirements specifically for the LBS sub-system. It analyzes the system into components/functions, which are in turn categorised into aspects of interaction (facets) with the user and levels of significance. The next step involves the mapping of the components to the four external quality sub-characteristics of the ISO9126 standard for quality evaluation, via the definition of a suitable correlation function. The mathematical foundation of the model permits the calculation of values for these weights that depict the importance of specific system features to the designers or to the users. Goal-oriented design is supported when evaluators set quality targets (weights) to facets, levels of significance and or quality characteristics. Users express their requirements by setting (through evaluation) the weights for functions and sub-quality characteristics. The use of formal standards for the evaluation of functions/components also enables the use of a common vocabulary across analysis, design and evaluation teams.

\section{REFERENCES}

[1] N. Ahmad, A. Rextin, U.E. Kulsoom,"Perspectives on usability guidelines for smartphone applications: An empirical investigation and systematic literature review," Information and Software Technology, vol. 94, pp. 130-149, 2018.

[2] P. Heck,A. Zaidman, "A systematic literature review on quality criteria for agile requirements specifications," Software Quality Journal, vol. 26(1), pp. 127-160, 2018.

[3] Q. Zheng, Y. Han, S. Li, J. Dong, L. Yan, J. Qin, "E-commerce Architecture and System Design," in Introduction to E-commerce, Q. Zheng Q., Eds. Berlin:Springer, 2009.

[4] ISO/IEC 9126: 2001, "Software engineering -- Product quality -- Part 1: Quality model". Zyrich: ISO, 2001.

[5] ISO/IEC 25010: 2011 "Systems and software engineering — Systems and software Quality Requirements and Evaluation (SQuaRE) System and software quality models", Zyrich: ISO, 2011.
[6] N.A. Ernst, A. Borgida, I.J. Jureta, J. Mylopoulos, "An overview of requirements evolution," in T. Mens, A. Serebrenik, A. Cleve eds. Evolving software systems. Berlin: Springer, pp. 3-32, 2014.

[7] S. Dhar, U. Varshney, "Challenges and business models for mobile location-based services and advertising," Commun. ACM, vol. 54(5), pp. 121-128, 2011.

[8] H.P. Breivold, I. Crnkovic, "Analysis of Software Evolvability in Quality Models," Software Engineering and Advanced Applications 2009, SEAA '09, 35th Euromicro Conference on, pp. 279-282, 2009, ISSN 1089-6503.

[9] W. Alsaqaf, M. Daneva, and R. Wieringa, "Quality Requirements in Large-Scale Distributed Agile Projects - A Systematic Literature Review," in REFSQ2017, 2017, vol. 10153, pp. 219-234.

[10] E. Parra, J.L. de la Vara, L. Alonso, "Analysis of requirements quality evolution," in Proceedings of the 40th International Conference on Software Engineering: Companion Proceeedings (ICSE '18), 2018, ACM, New York, NY, USA, pp. 199-200.

[11] A. Stefani, M.N. Xenos, "E-commerce system quality assessment using a model based on ISO 9126 and Belief Networks," Software Quality Journal, vol 16(1), pp. 107-129, 2008.

[12] J.D. Garofalakis, A. Stefani, V. Stefanis, "A Framework for the Quality Evaluation of B2C M-Commerce Services,'IJHCR, vol. 2(3), pp. 73-91, 2011.

[13] H.T. Kanwal, F. Arif, A.M. Zaidi, "Software requirement engineering a new leave towards the silver bullet," Science and Information Conference (SAI), pp. 189-198, 2015.

[14] D. Granlund, D. Johansson, K. Andersson, R. Brännström, "A Case Study of Application Development for Mobile and Location-Based Services," in Proceedings of International Conference on Information Integration and Web-based Applications \& Services (IIWAS '13), New York: ACM, 2013.

[15] S. Ilarri, E. Mena, A. Illarramendi, "Location-dependent query processing: Where we are and where we are heading," ACM Comput. Surv., vol 42(3), pp. 1-73, 2010.

[16] ISO/IEC 42010: 2011, "Software engineering -- Product quality -- Part 1: Quality model Systems and software engineering -- Architecture description". Zyrich: ISO, 2011.

[17] J.M.S. França, M.S. Soares, "SOAQM: Quality Model for SOA Applications based on ISO 25010," in Proceedings of the 17th International Conference on Enterprise Information Systems, vol 2 (ICEIS 2015), Slimane Hammoudi, Leszek Maciaszek, and Ernest Teniente eds.), Vol. 2. SCITEPRESS - Science and Technology Publications, Lda, Portugal, pp. 60-70, 2015. 